\title{
Construindo formas de habitar: memória e política no contexto revitalizado da região portuária do Rio de Janeiro
}

Resumo: A região portuária do Rio de Janeiro, logo após as obras de reestruturação urbana empreendidas pelo Projeto Porto Maravilha e após as escavações que trouxeram à tona o Cais do Valongo, tornou-se uma área tensionada e requerida como território étnico-cultural por uma variada trama de narrativas oficiais e não-oficiais. O processo de patrimonialização e musealização de uma "memória étnica" corrente pela região evidenciam em partes esse processo e lançam luz sobre os conflitos e tensões oriundos do exercício de se "habitar o patrimônio". Tendo em vista o nexo que se forma entre memória e política no contexto das redes de associativismo, vizinhança e sociabilidade, o objetivo deste artigo é apresentar, a partir de dois recortes etnográficos distintos, uma análise sobre as estratégias e "modos de habitar" a região portuária carioca pelos moradores locais, principalmente aqueles que residem nos limites entre o Morro da Conceição e o Morro da Providência, em um movimento, sobretudo, político.

Palavras-chave: Rio de Janeiro; zona portuária; memória; política; modos de habitar. 


\title{
Building ways of living: memory and politics in the revitalized context of the port region of Rio de Janeiro
}

\begin{abstract}
The port area of Rio de Janeiro, after the urban restructuring undertaken by the Porto Maravilha Project and after the excavations that brought up Valongo Wharf, became a tensioned area and required as an ethnic-cultural territory by a varied tangled official and unofficial narratives. The process of patrimonialization and musealization of current "ethnic memory" throughout the region highlights this process in part and sheds light on the conflicts and tensions arising from the exercises of "inhabiting the heritage". In view of the nexus that is formed between memory and politics in the context of network of associations, neighborhoods and sociability, the objective of this article is to present, from two different ethnographic accounts, analysis of the strategies and "ways of living" at carioca port area by residents, especially those who live on the borders between Morro da Conceição and Morro da Providência, in a movement, above all, political.
\end{abstract}

Keywords: Rio de Janeiro; port area; memory; politics; way of living.

\section{Construyendo formas de vida: memoria y política en el contexto de la revitalización de la región portuaria de Río de Janeiro}

\begin{abstract}
Resumen: La región portuaria de Río de Janeiro, justo después de las obras de reestructuración urbana emprendidas por el Proyecto Porto Maravilha y después de las excavaciones que llevaron al muelle de Valongo, se convirtió en una zona tensada y requerida como territorio étnico-cultural por una variada parcela oficial y no oficial. narrativas. El proceso de patrimonialización y musealización de una "memoria étnica" actual en toda la región resalta en parte este proceso y arroja luz sobre los conflictos y tensiones derivados del ejercicio del "patrimonio habitable". Ante el nexo que se forma entre memoria y política en el contexto de las redes de asociaciones, barrios y sociabilidad, el objetivo de este artículo es presentar, desde perspectivas etnográficas distintas, un análisis de las estrategias y "formas de vivir" en región portuaria carioca por parte de los residentes locales, especialmente los que viven en los límites entre Morro da Conceição y Morro da Providência, en un movimiento, sobre todo, político.
\end{abstract}

Palabras clave: Rio de Janeiro; zona portuaria; memoria; política; formas de vivir. 
I nicio este artigo trazendo para a análise duas situações etnográficas ocorridas em momentos distintos da minha trajetória de pesquisa, uma em 2006 e outra em 2012. Apesar da distância temporal existente entre elas, ambas ocorreram em um mesmo lugar: a região portuária do Rio de Janeiro, especificamente, nos limites do bairro da Saúde, entre os Morros da Conceição e Providência. Narrarei cada uma delas a fim de elucidar as circunstâncias para, em seguida, abordar os pontos que as conectam na análise antropológica.

Adianto que ambas foram observadas durante duas pesquisas distintas, uma para o mestrado e outro para o doutorado ${ }^{2}$ e que, embora distantes seis anos, elas compartilham entre si, para além do espaço territorial, a continuidade de uma obra pública, que foi a revitalização do cais do porto. É importante dizer, de antemão, que a zona portuária teve seu processo de povoamento mais intensificado a partir do século XVIII, quando o Rio de Janeiro se tornou capital da colônia e, com o crescimento da urbanização, algumas atividades comerciais passaram a ser desenvolvidas no litoral da Prainha (atual Praça Mauá) e da Saúde (primeiro bairro portuário, na divisão com o centro da cidade). O ponto mais alto do desenvolvimento da região deu-se com a transferência do mercado de escravos do centro da cidades para o Valongo, o que fez com que a região fosse incluída definitivamente nas atividades portuárias. Vale dizer, também, que ao longo dos anos, a região portuária do Rio foi palco de inúmeros projetos de revitalização. De acordo com Clarissa da Costa Moreira (2004), entre 1983 e 2001 foram elaborados sete planos de transformações voltados ora para o porto do Rio especificamente, ora para região portuária como um todo.

O Projeto Porto Maravilha, responsável por agregar e desagregar várias ações políticas, coletivas e sociais abordadas ao longo deste artigo, foi inaugurado a partir de uma Operação Urbana Consorciada nos primeiros anos da gestão de Eduardo Paes à frente da Prefeitura do Rio (2009-2013) e carrega em si alguns aspectos oriundos de gestões anteriores4.

Neste sentido, a proposta deste artigo é mostrar, a partir da experiência etnográfica, como memória e política se entrelaçam no processo de elaboração das redes de associativismo, vizinhança e sociabilidade, apontando as diversas estratégias que podem ser acionadas no exercício de habitar.

\footnotetext{
${ }^{2}$ De modo muito resumido, durante a pesquisa de mestrado (2007-2010), abordei as formas de sociabilidade e conflito existentes no Morro da Conceição, a partir do pedido de reconhecimento da Comunidade Remanescente do Quilombo da Pedra do Sal. A pesquisa foi aos poucos revelando construções políticas muito específicas do contexto local, que eram acionadas naquele momento (2006-2008) como resposta à possibilidade de eleição de Eduardo Paes à prefeitura do Rio e ao seu projeto de revitalização da área portuária. A pesquisa de doutorado (2010-2016) teve início em 2012, quando Paes, já eleito, tirava do papel seu projeto de revitalização da zona portuária. Meu intuito era, então, observar os desdobramentos dos eventos observados em 2008 à luz de ações políticas e movimentações locais que tomavam como base a contraposição entre memórias e narrativas oficiais e não oficiais sobre a cidade e a região, especificamente.

3 Antes de ser transferido para o Cais do Valongo, o mercado de escravos funcionava na antiga Rua Direita, atual Avenida Primeiro de Março.

$4 \mathrm{O}$ Porto Maravilha refletia principalmente as propostas elaboradas pelas gestões de César Maia, quando prefeito da cidade (1993-1997; 2001-2009), sobretudo o uso da parceria público-privada na administração urbana.
} 


\section{A Comunidade Remanescente do Quilombo da Pedra do Sal: composição de um território}

Localizada no sopé do Morro da Conceição, especificamente no Largo João da Baiana, bairro da Saúde, zona portuária do Rio de Janeiro, a Pedra do Sal é um monumento tombado pelo Instituto Estadual do Patrimônio Cultural (INEPAC), desde 1987. Seu discurso de tombamento, escrito pelo historiador Joel Rufino, refere-se a um "testemunho cultural mais que secular da africanidade brasileira”. Até o século XVIII, a região não havia sido aterrada, o que permitia que a Pedra estivesse bastante próxima do mar, a ponto de servir como local de descarga do sal vindo em embarcações aportadas próximas dali. A partir de meados do século XVIII, por conta da intensa movimentação oferecida pelos armazéns e trapiches existentes na região, o local passou a ser o foco da comercialização de africanos escravizados. Caracterizada, desde então, por uma forte presença negra, os registros e pesquisas históricas dão conta de uma intensa sociabilidade africana nos arredores da Pedra do Sal e do Valongo, promovida sobretudo por aqueles que, ainda escravos, se desdobravam nas mais variadas atividades, inclusive, naquelas relativas aos cuidados dos recém-desembarcados pelo tráfico negreiro (alimentação, cura, sepultamento)5.

"Devido a essas atividades, a região tornou-se, desde essa época, berço de práticas e rituais religiosos de matriz afrobrasileira”, escreve Maíra Leal Corrêa no fascículo "Pedra do Sal", da coletânea Terras de Quilombos (2016: 4) ${ }^{6}$, fruto do Projeto "Formulação de uma linguagem pública sobre Comunidades Quilombolas”, produzido a partir da parceria entre o Instituto Nacional de Reforma Agrária (INCRA) e a Universidade Federal de Minas Gerais (UFMG). Foi desse contexto que surgiu a denominação "Pequena África”, cunhada pelo sambista e pintor Heitor dos Prazeres e é com base nessa mesma ancestralidade que se ampara o pedido de reconhecimento da Comunidade Remanescente do Quilombo da Pedra do Sal.

O pedido, encaminhado à Fundação Cultural Palmares (FCP), no início dos anos 2000, trazia à tona um problema secular: a necessidade de garantir a moradia e a sobrevivência de famílias afro-brasileiras que permaneceram vivendo em condições precárias nos limites da zona portuária do Rio de Janeiro, desde o período da escravidão. O processo, envolto em complicações variadas, partia não apenas do interesse coletivo daquelas famílias em serem reconhecidas como quilombolas, mas também de um conflito territorial bem delimitado. As famílias eram locatárias de imóveis localizados nos arredores da Pedra do Sal havia muito tempo. Os aluguéis, contudo, não eram regulados por uma lógica fixa de mercado, o que conferia ao grupo uma vulnerabilidade extra no exercício de permanecer pela região, condição cara a todos os seus integrantes não apenas por questões afetivas, como também por questões práticas de trabalho e renda: os homens eram quase todos trabalhadores portuários, ocupando cargos simples na estiva e na arrumação, funções braçais historicamente designadas aos africanos e afrobrasileiros escravizados. As mulheres, por sua vez, dedicavam-se à comercialização de quitutes diversos nas ruas da região portuária do Rio, ocupações também descendentes do contexto da escravidão.

Pautado em uma demanda de urgência por permanência, o pedido de reconhecimento da comunidade quilombola contrapunha-se, a princípio, às ações empreendidas pela Venerável Ordem Terceira de São Francisco da Penitência

5 Sobre isso ver: Arantes (2010); Abreu e Mattos (2007); Corrêa (2016).

${ }_{6}^{6}$ Disponível em: http://antigo.incra.gov.br/media/docs/quilombolas/memoria/pedra do sal.pdf 
(VOT), que se designava proprietária dos imóveis em que moravam as famílias e era, então, a responsável pelo cobrança do aluguel. A VOT é uma organização de cunho religioso, católica, beneficente, educacional, de assistência cultural e filantrópica, fundada no Rio de Janeiro em 1619. No ano de 1897, o Padre Francisco da Motta, pertencente à VOT, ordenou a construção de uma igreja e de uma escola7 em terrenos localizados nas encostas do Morro da Conceição. Segundo documentos históricos, as terras em que tais construções foram erguidas foram repassadas ao Padre por meio de concessões e doações de Dom Pedro I ${ }^{8}$. Apesar do histórico de atividades de assistência voltadas a uma população carente existente na região, faltava à VOT documentos atualizados que comprovassem a posse dos imóveis que há pelo menos um século, ela alugava principalmente na forma de casas de cômodo.

A ausência dessa documentação, somada à inexistência de contratos formais de aluguéis entre a Ordem e seus locatários e, ainda, aos aumentos desmedidos dos valores a serem pagos, delinearam um cenário complexo e conflituoso no início dos anos 2000, quando a região portuária voltou a figurar na pauta de propostas políticas de revitalização. Além disso, as privatizações portuárias empreendidas no final do governo de Fernando Henrique Cardoso (1995-2002) serviram como um alerta ainda maior ao grupo de moradores da Pedra do Sal. Se a possibilidade da privatização portuária os fragilizava em termos econômicos, a proposta de reestruturação urbana da região do Porto do Rio os atingia em termos sociais e simbólicos, uma vez que, diante deste contexto, a especulação imobiliária fez aumentar a situação de vulnerabilidade em que se encontravam aquelas famílias, já desamparadas pela falta de contratos legais de aluguel.

É neste cenário de sucessivas fragilidades que Damião Braga Soares dos Santos, Marilucia da Conceição Luzia e Luiz Carlos Torres, se organizaram junto a outros vizinhos e recorreram ao pedido de reconhecimento como comunidade quilombola daquele grupo de moradores residente nos entornos da Pedra do Sal. As repercussões de tal pedido logo subiram as ladeiras do Morro da Conceição e acirraram os ânimos dos descendentes de portugueses e espanhóis que moravam na parte mais alta. As intrigas se intensificaram ainda mais em um dia, no final do ano de 2005, quando coordenadores da escola Padre Francisco da Motta, no horário da saída dos alunos, comunicaram aos pais ali presentes que "os quilombolas estão querendo tirar as nossas casas"9.

Cheguei ao Morro da Conceição, pela primeira vez, logo depois disso. O clima tenso se percebia na desconfiança dos olhares voltados não apenas para mim, mas para todas as pessoas que, porventura, passavam pelas ruas do morro, sem partilhar com os dali nenhum vínculo de familiaridade ou identificação. Além dos olhares, as falas ásperas sobre a situação das casas corriam também nos interiores dos bares e armazéns locais, mesmo nos momentos de lazer e distração. Se era verdade que mesmo ali as desconfianças com a escola da Ordem, a quem se atribuía a propriedade de certas casas no entorno, não eram simples, nem pequenas, também era perceptível que o desconhecimento sobre o que poderia ser uma comunidade quilombola no século XXI contribuía com o desconforto que pairava no ar.

Iniciei meu campo amparada por um casal de antropólogos que morava no morro e cujo contato prévio havia sido feito por um professor meu. $\mathrm{O}$ fato de o casal ser muito bem-quisto por ali e de sermos todos antropólogos, auxiliou-me

\footnotetext{
7 Igreja de São Francisco da Prainha e Escola Padre Dr. Francisco da Motta.

8 Para mais informações, ver Abreu e Mattos (2007).

9 Informações coletadas em campo, mas também constantes Abreu e Mattos (2007).
} 
bastante naquele primeiro período, mas não foi capaz de me deixar de fora de uma intrincada trama de fofocas que, com o tempo, percebi que funcionavam como recurso revelador da intimidade e da interdependência existentes entre os moradores. Os "casos de fofoca" evidenciavam o funcionamento das dinâmicas locais de convivência, ao mesmo tempo que serviam como um marcador da minha posição como alguém de fora daquele contexto, mas que deveria ser de alguma forma encaixada nas classificações existentes (COSTA, 2010) ${ }^{10}$.

A situação trazida pelo pedido de reconhecimento da comunidade quilombola explicitava as tensões constituintes das sociabilidades locais e também deixavam ver que morar por ali era lidar com situações limítrofes quase sempre. Se a presença da escola da Ordem cumpria a lacuna da ausência de outras instituições públicas de ensino voltadas à educação básica, por outro lado impunha a todos que convivessem com as investidas assistencialistas características da instituição, mas rejeitadas pelos moradores do Morro da Conceição. Faz-se necessário explicar, neste momento, que o Morro da Conceição figura na zona portuária carioca como um reduto mais elitizado e com maior poder aquisitivo do que o restante da região, que também congrega a primeira favela do Brasil, o Morro da Providência ${ }^{11}$. As oposições feitas entre os morros da Conceição e da Providência são várias e abarcam desde as questões estruturais que categorizam um como local resguardado como patrimônio cultural da cidade e o outro como favela, até as classificações simbólicas que entendem um como local de socializações elitizadas e outro como espaço do tráfico de drogas e da violência, ao qual devem ser voltadas as investidas assistencialistas, como as praticadas pela escola da Ordem.

Dessa maneira, se, por um lado, a escola da Ordem existente no Morro da Conceição desde o século XIX servia como argumento para confirmar a importância do patrimônio cultural local, por outro lado, as práticas adotadas pela gerência da escola impunham aos moradores do Morro da Conceição negociações classificatórias diárias, posto que não eram eles que necessitavam de propostas assistencialistas de ensino e convivência, mas sim os moradores do Morro da Providência, que não eram sequer considerados como vizinhos. Na visão corrente pela parte mais alta do Morro da Conceição, as ações da escola da Ordem "sujavam" a imagem que se deveria ter da vida ali. E sujavam de várias formas: pelos projetos assistencialistas; por trazerem mais para perto os moradores da favela; pela não regulamentação dos aluguéis, o que permitia que pessoas pobres (e pretas) alugassem casas por ali; pelo modo de aluguel das casas, seccionadas em cômodos, o que conferia um aspecto de encortiçamento ao entorno etc. Não eram raros, portanto, os casos de pais moradores do Morro da Conceição que rejeitavam as vagas existentes na escola da Ordem. Assim como também não eram raros aqueles que, por circunstâncias variadas, colocavam seus filhos para estudarem ali provisoriamente, até que conseguissem vagas em escolas tidas como melhores e mais distantes.

Assim, se a ameaça de que a comunidade quilombola poderia "tomar as casas" dos moradores do Morro da Conceição assustava a todos, também se discutia em conversas acaloradas pelos bares do morro que tudo aquilo havia sido incentivado e iniciado pelos próprios projetos da Ordem, "que alugava as casas por valores muito baixos". Contudo, se aos projetos da escola da Ordem cabia, ainda,

${ }^{10}$ A título de complementação, não são poucos os estudos antropológicos que se dedicaram a compreender os aspectos da fofoca, da intriga, das disputas e apostas como "reguladores da vida social”, basta ver: BAILEY (1971), HAVILAND (1977), FONSECA (2000), MARQUES (2002), COMERFORD (2003), entre outros.

${ }^{11}$ Muito embora existam relatos sobre cortiços ocupando as encostas do Morro de Santo Antônio e do Morro do Livramento, ambos no centro do Rio de Janeiro, desde meados do século XIX, é apenas em 1897, após a volta dos soldados combatentes na Guerra de Canudos, que o termo "favela" se populariza como sinônimo de moradia precarizada (cf. COSTA, 2016). 
um olhar mais benevolente, dado que partiam de uma organização religiosa, o mesmo não se podia dizer sobre a possível presença de uma comunidade quilombola na vizinhança. "Mas quilombos são coisas do século passado", "Como pode ter quilombo no centro da cidade se são coisas da zona rural?", "Como pode existir um quilombo no centro do Rio se a história diz que aqui em cima só viviam portugueses e espanhóis?”, esses foram apenas alguns dos vários questionamentos que ouvi a cada vez que, mesmo tímida, ousei perguntar detalhes sobre os moradores da Pedra do Sal. Com o correr do tempo e das dificuldades encontradas pela própria comunidade nas limitações burocráticas impostas pelo processo de titulação de terras no Brasil, muito dessa fúria inicial dos moradores das partes altas do Morro da Conceição foi sendo amainada. No meu retorno ao campo, em 2008, embora não se pudesse dizer que a comunidade quilombola convivesse de forma harmoniosa com o restante dos moradores do Morro da Conceição, também era verdade que os trânsitos entre os grupos pelos becos e vielas locais se davam de modo um pouco mais fluido, regidos, de forma geral, pela lógica da evitação e dos cumprimentos respeitosos. Era também verdade que, eventualmente, os moradores da parte alta do Morro desciam para prestigiar os eventos promovidos pela comunidade quilombola no Largo João da Baiana. Não iam animados, porém, por valorizarem os organizadores dos eventos, mas sim, pelas rodas de samba e comidas, que naqueles momentos, para eles, pareciam ganhar uma personalidade autônoma e desconectada dos quilombolas que as faziam existir.

Os desdobramentos desse cenário são vários e não devem ser abordados neste artigo $^{12}$. Interessa-me agora, apenas a observação sobre as estratégias políticas encontradas pela comunidade quilombola no período relatado para continuarem existindo e morando nos entornos da Pedra do Sal, na zona portuária do Rio de Janeiro. Retomarei essa discussão de modo mais detido ao final deste texto.

\section{As casas marcadas da Providência: entre o discurso do risco e a não-oficialidade da memória}

Era abril de 2012 quando me chegou o pedido para que fossemos todos até o salão da Igreja do Cruzeiro, no Morro da Providência. O pedido veio de uma das coordenadoras do Fórum Comunitário do Porto, movimento da sociedade civil organizada, criado especialmente no contexto das obras de revitalização da zona portuária do Rio. $\mathrm{O}$ foco das atividades do Fórum era discutir as remoções que se processavam a todo vapor por sobre um considerável número de casas da favela. Meu contato com o Fórum havia acontecido dias antes, na Vila Olímpica da Gamboa, para onde me dirigi quando, recém-chegada de volta ao Rio, soube que ali estavam acontecendo reuniões para se pensar a situação das obras de reestruturação urbana. Às 18h, peguei uma kombi na Central do Brasil, que subiu pela Ladeira do Faria, deixando a todos nos entornos da Praça Américo Brum. Até a igreja propriamente dita existia uma longa escadaria. Acompanhada de algumas pessoas participantes do Fórum, era a primeira vez que eu de fato subia até o ponto mais alto do Morro da Providência. Durante todo o meu campo de mestrado, concentrado entre os anos de 2006 e 2008, meus contatos com o Morro da Providência se davam a partir de seus moradores, com quem eu, ocasionalmente, encontrava nos arredores da Pedra do Sal.

${ }^{12}$ Outros detalhes podem ser vistos em Costa (2016). 
O cenário não era muito diferente daquele que eu podia ver a partir do Valongo ou da Ladeira do Pedro Antônio ${ }^{13}$, no Morro da Conceição, nem era, no fundo, tão distante do encontrado pelo Morro da Conceição. Casarões antigos, assobradados, com fachadas belas do final do século XIX também existiam por ali. Armazéns, bares e uma intensa sociabilidade fazia com que tudo parecesse levemente semelhante. As diferenças, fui percebendo conforme subia as escadas, nas marcas de tiros na encosta que ladeia toda a escadaria e no corrimão. Estar ali era adentrar um novo ambiente simbólico de significações negociadas no jogo duro que se forma entre o senso comum, que entende a vida na favela apenas como algo relacionado à violência, e a visão daqueles que habitam aquele espaço. Uma vez do lado de cima, na porta do salão da Igreja, encontrei Seu Nélio e Maurício Hora. Seu Nélio eu havia conhecido na minha ida à Vila Olímpica de dias antes, estivador aposentado, nascera e fora criado no Cantão do Morro da Providência e ali criara seus filhos e uma bateria mirim, a Mel do Futuro, feita há alguns anos, como forma de acolher a juventude local em atividades culturais relacionadas, principalmente, com o carnaval. Maurício Hora, por sua vez, eu havia conhecido ainda em 2008, durante o período mais intenso de meu campo de mestrado. Nos conhecemos no contexto dos festejos do dia o2 de dezembro, Dia Nacional do Samba, organizado pela Comunidade da Pedra do Sal. Maurício se apresentava sempre de um jeito instigante: "sou fotógrafo, favelado e quilombola", dizia. A firmeza de sua identidade me fizera compreender, desde cedo, a potência de cada uma dessas classificações.

Do lado de dentro do salão encontravam-se já reunidas algumas das pessoas que compunham o Fórum Comunitário do Porto. Eram muitas mulheres, quase todas vindas do curso de Serviço Social da UERJ, que encontraram ali um espaço não apenas para reflexões acadêmicas, como também para atuação social e política. Os contatos advindos de suas vinculações institucionais favoreciam, de certa forma, a proposta de resolução imediata dos conflitos oriundos das políticas de remoção, muito intensas naquela época. Inclusive, o motivo daquele encontro era o de debater uma reunião ocorrida no Núcleo de Terras e Habitação (NUTH), da Defensoria Pública do Rio de Janeiro. Desde 2011, o Morro da Providência vinha sendo alvo de ações de remoção por parte da Secretaria Municipal de Habitação (SMH) e o Fórum surgiu como um espaço intermediário, que buscava não apenas acolher os moradores da Providência que tinham suas casas marcadas para remoção, como também pensar soluções e impedimentos a mais essa situação de violência vivenciada por eles.

Já perto das 19h, as coordenadoras daquele encontro pediram para que todos entrassem no salão para darem início à roda de conversas. Elas queriam comunicar a todos sobre como tinha sido o encontro com o Núcleo de Terras e Habitação (NUTH) e traziam novidades favoráveis à comunidade como um todo, posto que uma denúncia pública contra as remoções e a violação aos Direitos Humanos havia sido protocolada na Defensoria. Queriam também pedir mais comprometimento da comunidade na participação das reuniões promovidas pelo Fórum. "O Fórum não faz sentido sem os moradores. Nós não somos uma representação dos moradores, não somos uma instituição de representação. É importante que vocês

\footnotetext{
13 Tanto no mestrado quanto no doutorado, optei por morar na região portuária do Rio, como uma forma de imersão no campo. Embora nas duas ocasiões essas imersões tenham se dado, a princípio, a partir de hospedagens em casas de conhecidos e amigos, foi sempre na Ladeira do Pedro Antônio, no Morro da Conceição, que eu fixei residência, depois de certo tempo e algumas buscas por acomodações mais coerentes com meu propósito de permanência para a pesquisa. A experiência de literalmente morar no campo significou, sempre, uma estratégia de acesso às redes e contextos locais bastante produtiva para alguém que vinha de fora da cidade, como eu.
} 
fortaleçam a Comissão dos Moradores junto ao Fórum, é um trabalho em conjunto", dizia uma das mulheres. Pedindo a fala, Seu Nélio relata a descrença de todos no enfrentamento às remoções:

\begin{abstract}
As remoções não podem ser um tabu', disse o prefeito Eduardo Paes no jornal essa semana. Nós estamos todos de mãos atadas. Quando a história das remoções começou, vieram muitos agentes do estado aqui, muita gente mesmo. Disseram que tinham criado uma tal de Comissão de Mediação de Conflito. Aí, quando [os agentes da prefeitura] vieram agora por último, eu fui falar com eles que tem casas aqui que não podem ser destruídas, tem famílias aqui que não podem ser removidas, gente muito simples, que não vai ter pra onde ir, que vai perder totalmente suas referências, que vai morrer na rua. Aí, eu lembrei dessa Comissão que tinha sido criada e perguntei onde estavam as advogadas dessa Comissão. E um rapaz lá, olhou pra mim e disse, fechando o guarda-chuva: 'os senhores não vão receber mais expediente dessa Comissão'. Eu olhei pra cara dele, fechei também meu guarda-chuva e fui embora. Nós não temos mais o que fazer. ${ }^{14}$
\end{abstract}

Na sequência da fala de Seu Nélio, um burburinho tomou conta do salão. Uma senhora, bem simples, sentada em uma cadeira escolar, disse que ninguém acreditava mais em nada e por isso ninguém queria fazer parte da Comissão de Moradores do Fórum, nem participava mais das reuniões. Um outro rapaz, tentando controlar a todos, disse que aquele era, então, o momento em que eles tinham que se apegar às memórias de suas vidas ali na Providência, porque eram elas as únicas capazes de trazer de volta a esperança e a resistência. E o rapaz seguiu dizendo:

Eles criaram o discurso do risco pra tirar a gente daqui. A favela tem 114 anos, essas famílias sempre moraram ali e nunca representaram risco pra ninguém, mas agora, como é conveniente pra eles expulsar o pobre do centro da cidade, pra construir um teleférico pra inglês ver, aí a gente vai virando risco. Mas a gente sabe contar a nossa história. ${ }^{15}$

O Relatório de Violação de Direitos e Reivindicações ${ }^{16}$, publicado em 24 de maio de 2011 e produzido pelo Fórum Comunitário do Porto, diz que desde fevereiro de 2011, a SMH iniciou a marcação dos muros frontais das moradias a serem removidas, sem abrir qualquer canal de esclarecimento e negociação coletiva e/ou individual com os atingidos. Alguns moradores receberam cartas de convocação para se apresentarem à $\mathrm{SMH}$, mas a grande maioria não possuía qualquer informação sobre os destinos de sua moradia e de suas vidas.

É importante frisar que tais ações não ocorreram a partir da apresentação e discussão conjunta de um plano de remoção e reassentamento, ocasionando, assim, várias situações de violação de direitos básicos, como o direito constitucional à informação, à inviolabilidade do lar e ao direito humano à moradia digna. (FÓRUM COMUNITÁRIO DO PORTO: 15-16)

A citação acima sintetiza as informações concernentes às remoções e ainda demarca a forma como informações importantes sobre um assunto demasiado sério eram repassadas naquela época, explicitando a inexistência de um espaço de intermediação entre as queixas dos moradores e o Estado. Quando iniciei meu campo ali na Vila Olímpica da Gamboa, fui movida pela continuidade das investigações iniciadas no Morro da Conceição e, apesar de minimamente conhecer as propostas da revitalização, os projetos voltados para o Morro da Providência eram uma incógnita. Em 2012, as casas do Morro da Providência já haviam sido marcadas pela Secretaria Municipal de Habitação e um documentário produzido

14 Notas e gravações de campo. 
por um coletivo artístico ${ }^{17}$ começava a circular entre os moradores. Muitos pesquisadores advindos das mais variadas áreas dedicaram-se a analisar minuciosamente os impactos e desdobramentos das políticas de remoções ${ }^{18}$.

Rafael Soares Gonçalves (2012) desenvolve uma interessante análise sobre a "construção social do risco" e a prática de remoção de favelas no contexto carioca, apontando para o fato de que as favelas estão historicamente relacionadas à noção de algum tipo de risco para a cidade, desde os discursos higienistas do início do século XX até aqueles que as relacionam com o risco da violência urbana. $\mathrm{A}$ percepção sobre a recorrência da associação entre favela e risco era algo bastante evidente nas falas nativas daqueles que tinham suas casas marcadas, ou que se mantinham à frente de associações e movimentos da região. Não raras vezes, vi serem acionadas memórias relativas à conjunção entre o "discurso do risco" e as intervenções ocorridas na favela, gerando, quase sempre, especulação imobiliária. As falas de Seu Nélio e do rapaz participante da reunião na Igreja do Cruzeiro deixam ver, de forma mais clara, como esse mesmo discurso vinha sendo acionado ali naquele momento.

Convém observar, todavia, que no período das remoções ocorridas na Providência, o discurso do risco propalado em linguagem oficial não acionava necessariamente uma postura higienista, nem tampouco se voltava a uma perspectiva da violência urbana - naquela ocasião, inclusive, o Morro da Providência contava com uma Unidade da Polícia Pacificadora (UPP) e, embora não houvesse cessado, o tráfico de drogas era então bem menos aparente. A fala do rapaz que participava da reunião narrada anteriormente é bastante marcada, ainda, pela concepção que associava a favela à violência, quase sempre proveniente da intrincada malha do tráfico de drogas, "essas famílias sempre moraram ali e nunca representaram risco pra ninguém”, ele diz.

Contudo, o discurso oficial em favor das remoções não apontava mais nesse sentido e era exatamente isso que fazia com que meus interlocutores se sentissem tão desnorteados, como se percebe na fala desanimada de Seu Nélio. Pela primeira vez, o "risco" ao qual estavam sendo associados aqueles moradores não era aquele com o qual historicamente haviam se habituado a lidar. O discurso das remoções vinha agora revestido de questões ambientais, ou "riscos geotécnicos", como por vezes se ouvia na fala dos engenheiros que trabalhavam no local. Nessa perspectiva, a remoção era uma questão de segurança para as pessoas, pois, teoricamente, as casas marcadas se encontravam em áreas de desabamento. Para os agentes públicos que atuavam ali diretamente, remover era uma forma de "resguardar" a vida daqueles moradores. Talvez por isso, a ausência de diálogos e o sumiço das esferas intermediárias para resolução de conflitos tenha ocorrido de forma tão linear e natural. Não parecia ser necessário muita explicação quando se dizia que as casas estavam prestes a cair.

Gonçalves (2012) observa como o uso indiscriminado da noção de risco ambiental reforça as representações negativas da favela, no caso da Providência, além do argumento ambiental, também se vislumbrava a justificativa técnica como um discurso de verdade incontestável em uma região supervalorizada pelo mercado imobiliário, que via na fachada histórica do patrimônio e do turismo por ele impulsionado uma alavanca econômica.

${ }^{17}$ Intitulado Casas Marcadas, o documentário foi lançado oficialmente em 2013 e foi dirigido por Adriana Barradas, Carlos R. S. Moreira e Alessandra Schimite.

${ }^{18}$ Gianella (2013), Gonçalves (2013), Cardoso (2013) são apenas alguns exemplos. 


\title{
Entrelaçando observações
}

Quando me aventurei a pesquisar a zona portuária nos idos de 2006, era comum encontrar por ali alguns historiadores, antropólogos e urbanistas cujas pesquisas versavam principalmente sobre o "porto negro", a "Pequena África”, o "patrimônio" e os "aspectos arquitetônicos" que caracterizavam as construções locais $^{19}$. Não era raro, portanto, que memórias fossem narradas como experiências do passado capazes de reconstituir experiências do presente, como testemunhos para fortalecer, debilitar e, também, complementar os discursos e os sentidos que se queria dar a determinados eventos (cf. HALBWACHS, 1990: 16).

Ao longo de meu campo de mestrado, em 2008, percebi que, eventualmente, para pequenos grupos de moradores locais, memórias também eram acionados como alicerces de ações políticas promovidas no presente. Era o caso, por exemplo, da Comunidade Remanescente do Quilombo da Pedra do Sal. A organização política dos moradores em torno da questão identitária pautava-se sobremaneira em uma complexa trama tecida entre memórias partilhadas e uma história oficial, e foi nessa chave de compreensão que o discurso de tombamento da Pedra do Sal como patrimônio foi usado para sustentar o pedido de reconhecimento da comunidade junto à Fundação Cultural Palmares e ao Instituto Nacional de Reforma Agrária (INCRA), em um período em que as circunstâncias políticas favoreciam a promoção da igualdade racial e de ações afirmativas ${ }^{20}$.

Subvertendo a lógica de regulamentação de populações e territórios quilombolas advindos das áreas rurais ${ }^{21}$, contexto em que muitas vezes as relações de parentesco e os usos da terra cristalizam o reconhecimento entre os membros e facilitam a identificação pelo Estado ${ }^{22}$, a Comunidade Quilombola da Pedra do Sal marcou sua identidade no centro da metrópole do Rio de Janeiro a partir de um processo de recuperação de memórias fundamental para a retomada de sua cultura, de suas "tradições" e, principalmente, de sua "ancestralidade”.

No relatório histórico-antropológico elaborado para o processo de reconhecimento e pedido de titulação da Comunidade da Pedra do Sal é possível ler:

\begin{abstract}
Em função do relatório antropológico e histórico apresentado, a área de referência do Quilombo da Pedra do Sal, entendido como área histórica de resistência negra à opressão histórica sofrida, compreende os marcos simbólicos e territoriais identificados com a memória e a história negras na região portuária, entre o Largo de São Francisco da Prainha e o Morro da Saúde: o território do mercado de escravos africanos, o Valongo; o cemitério dos pretos novos; o movimento do porto e de seus antigos armazéns, e a Pedra do Sal e seu entorno, com as memórias do samba e do santo. (ABREU e MATTOS, 2012)
\end{abstract}

O relatório citado explicita a predominância da Pedra do Sal e do trabalho portuário na configuração de uma territorialidade, que extrapola os limites técnicos de um território e adentra o universo simbólico das relações constituídas não apenas nas redes de parentesco, mas também nas de sociabilidade e religiosidade. Quando nas ocasiões em que precisava se apresentar, Maurício Hora se esforçava

\footnotetext{
19 Ver Arantes (2005 e 2010); Guimarães (2011); Vassallo (2012); Vassallo e Cicalo (2015); Moura (1995); Pereira (2007); entre outros

${ }^{20}$ É importante dizer que é também nesta mesma época que o Governo Lula criou a Secretaria de Políticas de Promoção de Igualdade Racial (SEPPIR), no intuito de promover a igualdade e proteger grupos étnicos afetados pela discriminação e pela intolerância, a partir de políticas públicas de ações afirmativas.

${ }^{21}$ Talvez seja necessário reforçar neste momento que, com base no artigo 68 do Ato das Disposições Constitucionais Transitórias e no artigo $2^{\circ}$ do Decreto 4887/2003 "consideram-se remanescentes das comunidades dos quilombos [...] os grupos étnico-raciais, segundo critérios de autoatribuição, com trajetória histórica própria, dotados de relações territoriais específicas, com presunção de ancestralidade negra relacionada com a resistência à opressão histórica sofrida", a quem devem ser garantidos os procedimentos de identificação, reconhecimento, delimitação, demarcação e titulação das terras ocupadas. Para maiores detalhes e informações, ver: http://www.incra.gov.br/estrutura-fundiaria/quilombolas

${ }^{22}$ Sobre isso, ver Mello (2012).
} 
por dizer-se "fotógrafo, favelado e quilombola", havia em sua fala mais do que um simples elencar de títulos, havia o esforço de esculpir um pertencimento e uma forma de habitar a região portuária do Rio de Janeiro, no contexto das vulnerabilidades a que estão expostos todos aqueles que remanescem na cidade.

Se para os quilombos rurais é a lida na terra que os identifica e une, na zona portuária carioca, é a atividade portuária o que os liga. No limite, não há distância entre ser favelado e ser quilombola no contexto portuário do Rio. A luta travada pela comunidade quilombola no processo de sua organização interna - com seus rearranjos de memória e a reconstrução de suas narrativas - frente às adversidades impostas pela burocracia da regulamentação jurídica e frente aos conflitos provenientes da sociabilidade, apesar do intervalo temporal, não difere em quase nada dos "movimentos" e "movimentações" 23 que passaram a se desdobrar pela zona portuária, principalmente no Morro da Providência, com a chegada do Porto Maravilha.

A eleição de Eduardo Paes à Prefeitura Municipal, em 2009, inaugurou uma fase de atenções voltadas à região portuária da cidade, intenção que se desenhava no contexto político municipal havia muito tempo. Nesse processo, intensificarem-se as políticas direcionadas à recuperação e valorização patrimonial da região, sobretudo do Morro da Conceição, mas não só isso, mais do que nunca, a administração urbana passou a ser regida pela lógica empresarial e vem daí o impulso para o desenvolvimento do potencial turístico da região como um todo. $\mathrm{O}$ pedido de reconhecimento da Comunidade da Pedra do Sal, em 2006, e as remoções vividas por uma parcela dos moradores da Providência, em 2012, evidenciam faces de um mesmo processo. Contudo, se por um lado os saberes sociotécnicos capturaram o patrimônio debaixo do discurso do risco embasando as remoções, por outro lado, os saberes insubmissos tomaram pra si a pertença étnica, no exercício de continuar a habitar a região portuária, a partir de um quilombo e dos lugares de memória, como a Pedra do Sal, o Cais do Valongo, o Instituto dos Pretos Novos e até o recente Museu da História e da Cultura Afro-Brasileira, dentre outros.

Ao ser retirado do papel, o projeto de reestruturação urbana da área do porto agrupou e reagrupou (e continua a fazê-lo, hoje quando escrevo) coisas e pessoas, atualizando a utilização de todo aquele território por uma variada rede de interesses e agentes, cujas narrativas estão fundamentalmente pautadas nesse tecido fino entre uma memória e uma história oficiais da cidade versus as memórias e histórias não oficiais de seus moradores. A fluidez dessas movimentações não se encerra e, menos do que procurar uma origem e um sentido exclusivo para o que segue acontecendo na zona portuária do Rio de Janeiro, o que se espera é entrever a história à luz da etnografia.

Recebido em 1 de outubro de 2020.

Aceito em 12 de dezembro de 2020.

${ }^{23}$ Aspas para o termo advindo do campo teórico. Nesse texto, o termo "movimentações" tem sentido aproximado ao desenvolvido por Ana Cláudia Cruz da Silva e serve exatamente para classificar a diversidade de investimentos aos quais meus interlocutores estão expostos, sem, no entanto, fixar suas identidades, como poderia sugerir a noção de "grupo" (e talvez até a própria noção de "associação", como a entende o senso comum) (ver SILVA, 2009). 


\section{Referências}

ABREU, M.; MATTOS, H. (orgs.). Relatório antropológico de caracterização histórica, econômica e sócio-cultural da Comunidade Remanescente do Quilombo da Pedra do Sal, 2007.

ABREU, M; MATTOS, H. "Relatório Histórico-Antropológico sobre o Quilombo da Pedra do Sal: em torno do samba, do santo e do porto". In: O'DWYER, E. C. (org.) O fazer antropológico e o reconhecimento de direitos constitucionais: o caso das terras de quilombo no Estado do Rio de Janeiro. Rio de Janeiro: Epapers, 2012.

ANDRELLO, G. Cidade do Índio: transformações e cotidiano em Iauaretê. São Paulo: Editora UNESP, 2006.

ARANTES, E. B. O Porto Negro: cultura e trabalho no Rio de Janeiro dos primeiros anos do séc. XX. Dissertação de Mestrado em História, Unicamp, 2005.

ARANTES, E. B. O Porto Negro: cultura e associativismo dos trabalhadores portuários no Rio de Janeiro na virada do XIX para o XX. Tese de Doutorado. História. UFF, 2010.

BAILEY, F. G. (org.). Gift and Poison.The Politics of Reputation. Oxford: Basil Blackwell, 1971

BENJAMIN, W. Obras Escolhidas - Magia e Técnica, Arte e Política. São Paulo: Editora Brasiliense, 1985.

CARVALHO, J. M. Os bestializados: o Rio de Janeiro e a República que não foi. São Paulo: Companhia das Letras, 1987.

CARDOSO, I. C. C. et al. (orgs.). Renovação urbana mercantilização da cidade e desigualdades socioespaciais. 01. ed. Rio de Janeiro: Mauad Editora, 2013.

CHALHOUB, S. Cidade Febril: cortiços e epidemia na Corte Imperial. São Paulo: Companhia das Letras, 1996.

COMERFORD, J. Como uma família - sociabilidade, territórios de parentesco e sindicalismo rural. Rio de Janeiro: Relume Dumará, 2003.

CORRÊA, M. L. Quilombo Pedra do Sal. Belo Horizonte: FAFICH, 2016.

COSTA, F. C. Morro da Conceição: uma etnografia da sociabilidade e do conflito numa metrópole brasileira. Dissertação de Mestrado. Antropologia Social. UFSCar, 2010.

COSTA, F. C. A revitalização da zona portuária do Rio de Janeiro: políticas, associativismos e movimentos. In: Actas Del X Congreso Argentino de Antropología Social. Buenos Aires, Editorial de La Faculdad de Filosofia y Letras, Universidad de Buenos Aires, 2011.

COSTA, F. C. Nas tramas da revitalização: conflitos e movimentos na zona portuária do Rio de Janeiro. Tese de Doutorado. Antropologia Social. UFSCar, 2016 
COSTA, F. C.; GONÇALVES, R. S.; BAUTÈS, N. Le Quilombo, l'Église et la Loi. Conflits et arrangements autour de l'appropriation d'un espace de mémoires. Annales de Géographie , 700: 1310-1337, 2014.

CARNEIRO DA CUNHA, M. Negros, estrangeiros. São Paulo: Brasiliense, 1985. CUKIERMAN, H. L. Yes, nós temos Pasteur: Manguinhos, Oswaldo Cruz e a história da ciência no Brasil. Rio de Janeiro: Relume Dumará/FAPERJ, 2007.

FAUSTO, B. Trabalho Urbano e Conflito Social (189o - 1920). São Paulo: Difel, 1977.

FERREIRA, A. O Projeto 'Porto Maravilha' no Rio de Janeiro: inspiração em Barcelona e produção a serviço do capital? Revista Bibliográfica de Geografia e Ciências Sociales. Serie Documental de Geo Crítica. Cuadernos Críticos de Geografia Humana (Barcelona), XV (895), 20, 2010

FONSECA, C. Família, fofoca e honra: etnografia das relações de gênero e violência em grupos populares. Porto Alegre: Editora da Universidade/UFRGS, 2000.

FÓRUM COMUNITÁRIO DO PORTO. Relatório de violações de direitos e reivindicações, 2011.

GIANELLA, L. A produção histórica do espaço portuário da cidade do Rio de Janeiro e o projeto Porto Maravilha. Espaço e Economia [Online], 2013

GONÇALVES, R. S. A construção social do risco e as remoções das favelas cariocas. In: Anais do $36^{\circ}$ Encontro Anual da Anpocs. Águas de Lindóia: São Paulo, 2012.

GONÇALVES, R. S. Favelas do Rio de Janeiro: história e direito. Rio de Janeiro: Pallas: Ed. PUC-Rio, 2013.

GUIMARÃES, R. S. A utopia da Pequena África. Os espaços do patrimônio na Zona Portuária carioca. Tese de Doutorado em Sociologia e Antropologia, UFRJ, 2011.

HALBWACHS, M. A memória coletiva. São Paulo: Edições Vértice, 1990.

HAVILAND, J. B. Gossip, Reputation and Knowledge in Zinacantan. Chicago:The University of Chicago Press, 1977.

HERZFELD, M. Cultural Intimacy. Social Poetics in the Nation-State. New York/ London: Routledge, 1996.

HONORATO, C. P. Valongo: o mercado de escravos do Rio de Janeiro, 758 a 1831. Dissertação de Mestrado em História, UFF, 2008.

LÉVI-STRAUSS, C. "O problema das descontinuidades culturais diante da Etnografia e da História”. In: Antropologia Estrutural Dois. Rio de Janeiro: Tempo Brasileiro, 1993.

LÉVI-STRAUSS, C. O pensamento selvagem. São Paulo: Papirus, 1989.

LIMA, T. S.; GOLDMAN, M. “Prefácio'. In: CLASTRES, Pierre. Sociedade contra o estado. São Paulo: CosacNaify, 2003.

MARQUES, A. C. Algumas faces de outros eus. Honra e patronagem na Antropologia do Mediterrâneo. Mana, 5 (1), 1999. 
MARQUES, A. C. Intrigas e questões: vingança de família e tramas sociais no sertão de Pernambuco. Rio de Janeiro: Relume-Dumará/NuAP (Coleção Antropologia da Política), 2002.

MELLO, M. M. Reminiscências dos quilombos: territórios da memória em uma comunidade negra rural. São Paulo: Terceiro Nome, 2012.

MINTZ, S. W. "Houses and Yards Among Caribbean Peasantries". In. MINTZ, Caribbean Transformation. Londres: The John Hopkins University Press, 1984.

MOREIRA, C. C. A cidade contemporânea entre a tabula rasa e a preservação: cenários para o porto do Rio de Janeiro. São Paulo: Ed. UNESP, 2004.

MOURA, R. Tia Ciata e a Pequena África no Rio de Janeiro. Rio de Janeiro: Secretaria Municipal de Cultura, 1995.

NORA, P. Entre memória e história: a problemática dos lugares. Projeto História, 10 (10): 7-28, 1993.

PEREIRA, J. C. M. S. À flor da terra: o cemitério dos pretos novos no Rio de Janeiro. Rio de Janeiro, Garamond/IPHAN, 2007.

SILVA, A. C. C. Militância, cultura e política em movimentos afro-culturais. In: Revista de Antropologia, 52 (1), 2009.

VASSALLO, S. P. "De ossadas a patrimônio afrodescendente: a criação do Instituto dos Pretos Novos na Zona Portuária do Rio de Janeiro". In: $28^{a}$ Reunião Brasileira de Antropologia, São Paulo, julho de 2012.

VASSALLO, S. P. "Desenterrando memórias: uma análise das disputas em torno de sítios arqueológicos afrodescendentes na Zona Portuária do Rio de Janeiro". In: Anais do $36^{\circ}$ Encontro Anual da Anpocs. Águas de Lindóia: São Paulo, 2012. VASSALLO, S. P.; CICALO, A. Por onde os africanos chegaram. Horizontes Antropológicos, 21 (43): 239-271, 2015.

VIVEIROS DE CASTRO, Eduardo. O nativo relativo. Mana, 8 (1): 113-148, 2002.

\section{Documentário:}

Casas Marcadas, 2013.

Direção.: Adriana Barradas, Carlos R. S. Moreira e Alessandra Schimite. 


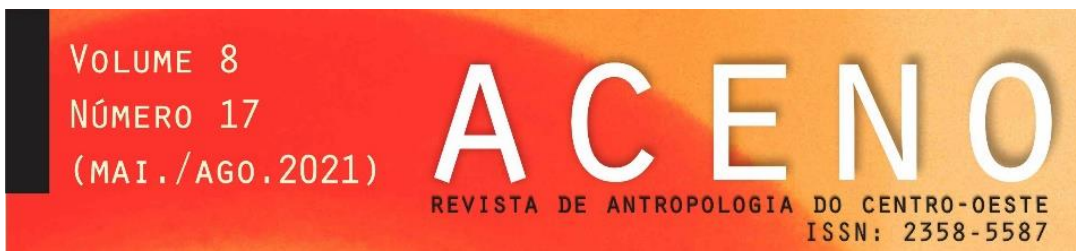

CHAMADA DE ARTIGOS DOSSIE TEMATICO:

RETOMADAS E RE-EXISTÊNCIAS

INDÍGENAS, NEGRAS E QUILOMBOLAS

COORDENADORXS:

SONIA REGINA LOURENÇO (PPGAS/UFMT)

CAUE FRAGA MACHADO (NUPACS/UFRGS)

SANDRO JOSE DA SILVA (PGCS/UFES)

ste dossiê temático da ACENO tem como objeto as territorialidades e os processos de identificação negras, quilombolas e indígenas. A proposta busca chamar a atenção para processos de identificação e territorialização que forneçam perspectivas adicionais às análises consolidadas que se dedicaram às tradições, à etnogênese e às situações de fronteiras étnicas, mais afeitos às mediações com o Estado-nação, que privilegiaram as relações políticas, agentes e agência da burocracia.

Um movimento renovado de coletivos indígenas, quilombolas e negros tem revisitado tais abordagens mediante a crítica sistemática aos padrões eurocentrados, brancos e coloniais que produziram a invisibilização sistemática do que esses movimentos consideram relevantes. Dentre essas, categorias como "retomada" e "resistência" - não apenas como reação, mas como re-existir - territorial e existencial são fundamentais quando tomadas como conceitos que descrevem diferentes vínculos entre actantes dos mais diversos modos de existência.

A proposta privilegiará a publicação de etnografias e reflexões teóricas acerca desse novo cenário no qual entes produzem reflexões cosmopolíticas e modos de agir com (ou contra) o Estado-nação de modos antes insuspeitos. Espera-se que as contribuições contemplem a diversidade regional, étnicoracial e de gênero, bem como contribuições dos povos originários e povos e comunidades tradicionais.

Trata-se de consolidar olhares não pela via da memória ou da prova, mas

PRAZO FINAL

DE SUBMISSÃO: pela cosmologia e relacionalidade estendida a todos existentes, recuperando

cordido ou inexistente. Pretende-se de sublinha

30 DE ABRIL identificações e territorialidades que encontram novas maneiras de se

DE 2021

expressar, retomando terras, práticas, contato com seres, objetos, linguagens sem que essas nunca tenham sido perdidas de fato. 